condition is regarded as especially fatal may be due to the scarcity of those cases in which a diagnosis is possible. The only instance of recovery from such a condition that I have been able to find is one recorded by Voorman and quoted by Dr. Gowers $;^{2}$ in this case the patient was a child aged five months, and the recovery was incomplete.

East Greenwich, S.E.

\section{SPASMUS NUTANS.}

By GILBERT A. BANNATYNE, M.D. GLASG., gONORARY PHYSICIAN, ROYAI MINERAI WATER HOSPITAL, BATH.

SPAsmus NuTANs, or head-nodding, while comparadively rare in children, is almost unknown in adults. Except the cases mentioned by Dr. McGillivray of Dundee, ${ }^{1}$ have failed to find any mention of it in the literature at my command. Possibly, therefore, the report of such a unique condition may be of interest to some of the readers of WHE LANCET. For details of the disease in children I would refer them to Henoch, ${ }^{2}$ who was the first to point out the features of the disorder, and to the papers of Dr. Stephen Mackenzie, ${ }^{3}$ Dr. Gee, ${ }^{4}$ Dr. Hadden, ${ }^{5}$ and Dr. G. Dickson."

A man aged forty-three was admitted to the Bath Royal Mineral Water Hospital on Aug. 30th, 1895, suffering from pains in the back and right hip, with lateral spasmodic morements of the head and eyes. According to the report furnished by his medical attendant the patient had suffered from rheumatism and sciatica from about the middle of May and had been steadily getting worse up to the time of admission. He also stated that the patient had suffered from nystagmus from birth. On admission the patient stated that fifteen years previously he had what he thinks was an acute attack of rheumatism; since then he had been free from it until the onset of his present illness. There is no history of syphilis, either inherited or acquired ; the family thistory is good. He complained of pain about the right hip and down the course of the right sciatic nerve, and to a less extent over the lower lumbar spines. His complexion is unusually fair, but he is not an albino. On examining the joints no changes were detected, the movement being free, and on passive movement there was no pain. There was no pain or tenderness down the course of the sciatic nerve, and there was no wasting or other sign of nerve degeneration. Sensation was normal, and the reflexes were active. Over the lumbar spines some slight tenderness was obtained on deep palpation. At the same time, although not complained of, it was noticed that he suffered from horizontal nystagmus of both eyes, with internal strabismus of the right eye and lateral escillation of the head. On inquiry these symptoms would appear to have existed as long as he could remember and, he believed, from birth or soon after. No cause could be given for its onset, and as far as he knew he never was seen by a medical man. He stated that it had not altered much in degree or character, and had never been sufficient to interfere with his work. His schooling seemed to have been of the scantiest. At times he was troubled with a feeling of weight and heaviness in the head, principally on the right side. For years he had been subject to sudden attacks of partial loss of consciousness. These were unaccompanied by any premonition and usually made him either fall backwards or at least clutch at something to prevent him from falling. He never became quite unconscious and had rever hurt himsolf. The fits at their worst occurred as often as twice or thrice a week. They became worst during the five years from 1888 to 1893 , after which they gradually became fewer and have now entirely ceased. The other symptoms have altered little. The movements of both head and eyes became worse when he was excited or when his attention was drawn to them. They ceased during sleep and to a certain extent when lying down - that is to say, whilst in the recumbent position the movements of the head ceased entirely, whilst those of the eyes became slower and not so frequent. On closer examination it was seen that the first movement of both eyes and head was to the left, and the divergence was

2 Diseases of the Nervous System, vol. ii., p. 420. 1888. 1 Ophthalmic Review, August, 1895

Diseases of Children. Translations of the Sydenham Society. 3 The LaNCET, May 1st, 1886

4 St. Bartholomew's Hospital Reports, vol. xxii., 1886.

THE LAXCET, June 14th, 21st, and 28th, 1890. The LAveET, Oct, 5th, 1895. certainly greater to that side of the middle line than to the right. The movement was entirely of a horizontal nature. The movements of the head and of the eyes did not correspond with each other either in number or in rhythm; the eyes oscillated from 80 to 100 times per minute, whereas the head only did so from 20 to 30 times, or it might be even less if his attention was taken up by other things. He had little control over either movement, the mere fact of trying to control them at times seeming to bring them more into evidence. This became so marked that now and then twitching of the left facial muscles occurred. The strabismus also at those times became more marked. Mr. W. M. Beaumont kindly examined the patient's eyes for me, and he reports that there is "well-marked horizontal nystagmus of both eyes, exaggerated if the eyes are deviated either to the right or left. There are also frequent lateral or slightly rotatory movements of the head not synchronous with the nystagmus and somewhat irregular. He appears to be able to control the movements to a slight extent, and they cease when he lies down. The nystagmus does not cease when he lies down. Interior of the eyes by ophthalmoscopic examination: There is a delicate veil-like opacity of the vitreous, with fine particles floating about. The choroidal vessels are seen very clearly (he is an extremely fair man, with light-yellow hair, but not albinic), and in each eye there are more than twenty dioptres of myopia, with posterior staphyloma. His vision cannot be improved beyond $\frac{b}{6} \sigma$. The bad vision and nystagmus are said to be congenital." Treatment consisted in a course of the mineral waters, both externally and internally, with iodide of potassium. On Oct. 10th the patient expressed himself as feeling quite well, being free from all pain and also of the feeling of weight in the head. He stated that he was as well as he had ever been, and, being anxious to return to work, he was discharged. Little or no change occurred during treatment. in the head and eye symptoms, and one may safely say that in all probability they will remain for the rest of his life.

Remarks.-Looking at the case as a whole it may, I think, be classed with those to which the somewhat misleading term of "spasmus nutans" has been given. In saying that the name is misleading I mean in so far as it implies that the head is nodded, for in a certain proportion of cases the motion is not from back to front, but from side to side, and, therefore, strictly the term should not be applied. It has been given, however, and has come to be associated with a sufficiently well-marked series of symptoms, and it would be a pity to add confusion by applying a new term to those cases in which the movements are lateral, as has been suggested. The question of diagnosis must remain for the present undecided. I am not inclined to believe that this is only one of the many forms in which epilepsy is manifested, but rather think that it is a disease per se. It must be borne in mind that head movements with nystagmus are fairly common in grave nerve disorders merely as symptoms. Whether, when they occur, as in the above case, unaccompanied by other symptoms, they are to be regarded as constituting a regular disorder or only as a group of symptoms having a deeper significance must for the present be left alone. The points of most interest in the symptoms are their persistence, the lateral character of the movements, the attacks of petit mal, the facial twitching and strabismus, the fair complexion, and the pain and tenderness over the spine. The outstanding feature is undoubtedly the persistence of the symptoms. In almost all the cases hitherto reported the disease has proved to be transitory, seldom lasting more than a few weeks and ceasing, as a rule, when some reflex exciting cause has been removed. With the exception of three cases described by Henoch ${ }^{7}$ and nine mentioned by Dr. McGillivray, ${ }^{\prime}$ all the other cases hitherto reported have been under two years of age and mostly under one at the beginning of the attack. As a rule, it has lasted for from a few days to several months, but with the exception of the cases mentioned never longer. Henoch's three cases were seen respectively at the ages of nine, ten, and twelve. In only one was the onset fixed, which was a year and a half before coming under observation; the other two cases were accompanied by other symptoms pointing to central nerve disease, and therefore cannot be regarded as pure cases. The cases of Dr. McGillivray are of much interest. Eight occurred in one family in four generations, thus establishing a hereditary tendency in the 
complaint. It was apparently transmitted by the female side, skipping one or more generations, more often than by the male. The disease was congenital, and in all cases persisted throughout life. 'The other case occurred associated with three others in which lateral nystagmus only was developed, and it would look as if the nystagmus were an early or not so fully developed condition. In Dr. McGillivray's cases the sight was usually affected. In the case under consideration it is not only seen in an adult, but from the history given it cannot be doubted that it came on early in life and had since persisted without intermittence. It was likewise unaccompanied by any further symptom pointing to other and more grave nervous trouble. Is it to be classed with those of Dr. McGillivray in so far as to call it congenital (no direct evidence exists that it was so), or is it to be classed with those of Henoch and others? There is, on the one hand, no history of heredity, and, on the other, it is a mystery why it should have persisted. Henoch and Dr. Hadden are of opinion that it arises from reflex impulses set up by disordered dentition or other slight irritation in the earlier months of childhood. This patient in all other respects is a strong, healthy man, and has hitherto been quite capable of carrying on his somewhat arduous occupation. The family bistory affords no clue. He is married and has healthy children, and there is no history of syphilis, either inherited or acquired, and no epilepsy. It must be presumed that it originated in some hitherto unexplained way, but probably in the manner suggested by Henoch. Next in order is the direction of the movements. In the large proportion of cases hitherto reported these have been of a nodding character ; in some, however, this character has been modified by a more or less lateral movement, producing a rotatory spasm, and in a smaller proportion there has been a pure lateral movement. The eye movements as a rule correspond in direction with that of the head. In this case the motion was undeniably first to the left, showing that the spasm commenced in the left muscles; but one could not determine whether the corresponding spasm on the right side was only an induced and subsidiary spasm or an independent one. I am inclined to think that probably the right-hand spasm was purely sympathetic. The facial twitching I have not seen mentioned in any other report, and it is probably only a further extension of the disease. It did not occur so frequently and was not so marked as the heal spasm, being usually brought on by excitement. The strabismus only occurred during excitement, but apart from the disease the condition of the eyes themselves was sufficient to account for it. What was described as rheumatic pain was, I take it, entirely nervous in origin, there being no joint or other rhemmatic phenomena. Henoch states that the disease arises from some reflex irritation such as dentition acting on an unstable nerve system. This belief would appear in the majority of cases to be well founded, as many, if not all, seem to be cured on the removal of the ixritating cause. If the disease is looked at as a whole the significance of the attacks of petit mal is increased. It points to some lesion on the surface of the brain rather than to one involving the nerve roots. As I have explained, I do not consider the head and eye oscillations to be mere, however rare, symptoms of epilepsy, but rather that they all have a significance in common. In this and similar cases probably what was at first only an instability of the ultimate nerre elements has passed insensibly into actual organic change. In hereditary cases this instability would be all the more marked and slighter exciting causes would bring about the onset. Probably the disease would prove more resistant to treatment and more likely to take on a permanent character. The lesions probably might be localised in the first and second frontal convolutions, as in monkeys. In these animals a centre for the movements of the head and eyes has been found to exist in that locality; tho centre for the facial movements lies in the lower third of the ascending frontal, and therefore, if the face be implicated, the lesion, although silight and superficial, must affect a comparatively extensive area. As to the nature of the irritation, although very fair, the patient is not an albino, but it is rather suggestive that in albinism nystagmus is common through the early visual impressions being painful and of disturbing excess through the absence of jigment. Such ideas open up endless vistas of theories, which can in the present state of os knowledge only end in theories. Taking the disease en massu. it appears to me to be due originally to some over-action of certain nerve cells, with induced spasms in certain muscles, producing oscillation of the head and eyes, and at times through some sudden discharge of nerve energy giving rise to regular attacks of petit mal. The occurrence of the latter symptom is a good guide to what is going on, as it is knowr. that it is due to a sudden liberation of nerve force. Experiment has taught that petit mal can be produced by irritating the cells of the cortex and thereby causing over-action of these cells and a sudden discharge of their energy. TY€ probability is that in such cases as have been described there is an initial defect in the cortical cell nutrition, which, beirg determined by some reflex irritation, passes first into a temporary state of increased activity and, if the irritation be severe enough or be sufficiently long continued, of actua organic change. I hope I have made my views sufficiently clear, and I reiterate that I consider the affection a disease per se and not merely a subsidiary form of epilepsy. Bath.

\section{Clinital Antes:}

\section{MEDICAL, SURGICAL, OBSTETRICAL, AND THERAPEUTICAL.}

\section{PHLEGMASIA ALBA DOLENS IN THE VIRGIN.}

By DAxiel Mowat, M.D. EDIN.

THE case described by Dr. Herman in THE LANCET of Oct. 5th recalls a similar one which occurred in my practice in January last. The patient was eighteen years of age, tall, and slightly anæmic; her menstruation was regular but somewhat scanty; she had no cardiac trouble. She was suddenly seized with pain in the right thigh, shortly after which the leg began to swell. The patient became unable tn walk, and the temperature rose. The leg presented the usut appearance of "white swelling." There was no trace (f sugar or albumin in the urine. Under treatment the limb began to recover, but it was several weeks before thit patient was able to stand. Last September she had a sliglt return of the phlegmasia in the same leg. Dr Herman: case is still more interesting as both legs were affected, the one becoming swollen as the other recovered.

Stamford-hill, N.

\section{A. CASE OF QUINTUPLETS.}

BY J. W. S'Toker, L.R.C.P. \& S. EDIN., L.F.P.S. GLasG.

THE patient was a woman aged thirty-five years, $5 \mathrm{ft} .1 \mathrm{in}$ in height, of very slight build, and healthy. Her mother had given birth to twins on two occasions; apart from this no further family history has been ascertained. She had been married for six years and had borne four children at full period, and never had any difficulty in labour Coming to the present case the patient computed that she had heen pregnant for six months and said she conld not understand why she felt much bigger than on former occasions. She complained of a pain (fixed) in the left sire of her abdomen, and imagined that she was larger on the same side. Otherwise she felt well up to two days befor her confinement. Labour set in on Sunday, Oct. 20th, 10 P.M., and was concluded on Monday at 6.45 A.M. On that day the pains were regular, though not strong, and the con tractions good. On my arrival at $3 \mathrm{~A} . \mathrm{Mr}$. the patient wa strongly in labour, and on making an examination $I$ found the membranes ruptured and a shoulder presenting. There was n difficulty in performing version. The child was dead (recent) On making an examination after the lirth of the first child easily became aware of the existence of more than ol: remaining foetus. The membranes protruded and becan tense at each pain. The presentation was a transrerse on In this case, also, there was not much difficulty in perforn ing internal version. The child was alive and lived a com! of hours. The third foetus was also enclosed in a separit bag, which required to be ruptured. This was a breech pl sentation, and the child was delivered naturally, being at, as? surviving for an hour. In the fourth case the same ceaure of rupturing the membranes was gone througin, an immediately there was hæmorrhage to an alarming terteLt 